\title{
FORMAÇÃO DE PROFESSORES DE EDUCAÇÃO INFANTIL: A EXTENSÃO UNIVERSITÁRIA COMO ESPAÇO DE DIÁLOGO E EXPERIÊNCIAS
}

\section{TRAINING OF CHILDREN EDUCATION TEACHERS: UNIVERSITY OUTREACH AS A SPACE FOR DIALOGUE AND EXPERIENCES}

\author{
Daiana Camargo* \\ ORCID: https://orcid.org/0000-0002-1931-5577. \\ Marilúcia Antônia de Resende Peroza** \\ ORCID: https://orcid.org/0000-0002-2733-5244
}

\section{Resumo}

O presente texto discute a importância da extensão universitária para o aprofundamento da formação docente e a propagação e ampliação de conhecimentos acadêmicos. A interlocução entre a Universidade e as instituições de Educação Básica, prerrogativa na articulação entre teoria e prática, torna-se realidade na medida em que se criam espaços que possibilitam o diálogo e a troca de experiências entre sujeitos em formação e aqueles inseridos no cotidiano escolar. Apresentam-se os resultados do projeto de extensão "A primeira infância e as práticas pedagógicas: entre o pensar e o fazer", como uma iniciativa que favorece um aprofundamento na formação de professores. Toma-se como base as contribuições de Castro (2004), Rocha e Ostetto (2012), Dalmolin e Vieira (2015), entre outras. As avaliações dos participantes do projeto de extensão evidenciaram a importância desta formação tanto para acadêmicos quanto para professores da rede pública de ensino, apontando a necessidade de continuidade na proposta.

Palavras-chave: Formação de professores; Educação infantil; Extensão universitária; Prática pedagógica.

\begin{abstract}
This text discusses the importance of university outreach programs for a further developement of teacher education and the spread and expansion of academic knowledge. The dialogue between the University and the Basic Education institutions, a prerogative in the articulation between theory and practice, becomes reality as it creates spaces that enable dialogue and the exchange of experiences between subjects in training and those inserted in the school routine. The results of the outreach project "Early childhood and pedagogical practices: between thinking and doing" are presented, as an initiative that favors further training of teachers. It takes as a basis the contributions of Castro (2004), Rocha and Ostetto (2012), Dalmolin and Vieira (2015), among others. The evaluations of the participants in the project showed the importance of this training for both academics and public school teachers, pointing out the need for continuing the proposal.
\end{abstract}

Keywords: Teacher education; Child education; University outreach; pedagogical practice.

Data recebimento: $14 / 10 / 2020$

Data de aceite: $06 / 05 / 2021$
* Professora da Universidade Estadual de Ponta Grossa (UEPG), Ponta Grossa - PR, Brasil. E-mail: camargo.daiana@hotmail.com

** Professora da Universidade Estadual de Ponta Grossa (UEPG), Ponta Grossa - PR, Brasil. E-mail: malu.uepg@gmail.com 


\section{Introdução}

Registrar e socializar uma proposta exitosa de ampliação das possibilidades de compreensão e valorização de uma importante área de formação do currículo do curso de Pedagogia da Universidade Estadual de Ponta Grossa - PR (UEPG) é a primeira intenção deste texto. Para tanto, discorremos sobre o contexto e os caminhos percorridos entre a elaboração da proposta, as experiências vivenciadas e a avaliação, o que nos apontou a necessidade de continuidade deste projeto.

Nas últimas décadas, de modo especial a partir da aprovação da Lei de Diretrizes e Bases da Educação Nacional (LDBEN n ${ }^{\circ}$ 9.394/96), a Educação Infantil e, consequentemente, a formação de professores para atuar na primeira etapa da Educação Básica têm sido foco de pesquisas e do crescente aumento no número de publicações acadêmicas. No entanto, as discussões engendradas no interior dos cursos de formação inicial de professores ${ }^{i}$ ainda têm apresentado sinais tímidos de mudanças no sentido de possibilitar aos acadêmicos tanto uma visão aprofundada sobre o processo educativo das crianças pequenas quanto pautar uma sólida constituição da identidade docente para atuar na Educação Infantil, como destaca Dias de Lima (2015).

Compreendemos que estes desafios estão associados, por um lado, ao recente reconhecimento da Educação Infantil como parte da Educação Básica, que ocasionou uma tardia discussão sobre o cotidiano das instituições que atendem crianças e, nele, as especificidades da formação de professores para atuar em creches e pré-escolas. Os estudos de Azevedo (2013) e Dias de Lima (2015) enfatizam que os currículos dos cursos de Pedagogia, de forma geral, não oferecem uma sólida formação para a docência na primeira etapa da Educação Básica. Não obstante, as produções das diferentes áreas de conhecimento sobre a criança, a infância e as práticas pedagógicas na escola de Educação Infantil têm contribuído para um repensar da formação inicial e continuada de professores.

Diante desta realidade e observando as lacunas que se evidenciam na formação de professores no âmbito do curso de Pedagogia, encontramos na extensão universitária uma forma de ampliar e aprofundar a formação dos acadêmicos no que se refere à prática pedagógica desenvolvida em creches e pré-escolas. Esta formação se torna mais significativa quando se possibilita aos professores das redes municipais participarem da extensão, propiciando reflexões que articulam a teoria e a prática, uma vez que promove o encontro entre sujeitos em processo constante de aprender-ensinar (PEROZA; CAMARGO, 2019).

A realização do projeto de extensão “A primeira infância e as práticas pedagógicas: entre o pensar e o fazer" emerge dessa necessidade de aprofundamento dos estudos na área de educação infantil observada ao longo do processo de formação dos acadêmicos, bem como do desejo expresso de professores e equipes pedagógicas do município no qual a universidade se localiza, e de municípios vizinhos dos quais advêm os acadêmicos, de ampliar o conhecimento teórico-prático na área. Entendemos que as disciplinas do curso contribuem com o processo de formação dos licenciandos, no entanto, a experiência tem mostrado que ainda não são suficientes para dar maior segurança para os futuros profissionais da Educação Infantil. Por outro lado, as secretarias municipais de educação da região propõem formação continuada, mas, muitas vezes, em temáticas que não suprem as necessidades impostas pelas práticas cotidianas nas instituições de Educação Infantil. 
De modo especial, no desenvolvimento do Estágio Curricular Supervisionado - pelo fato de termos diante de nós os acadêmicos e os professores na prática cotidiana -, observamos que algumas temáticas necessitavam de maior aprofundamento de estudos e compreensão, tais como as práticas pedagógicas direcionadas às crianças da creche (crianças de 0 a 3 anos) e da pré-escola (crianças de 4 e 5 anos); o trabalho com as múltiplas linguagens; o brincar; o corpo e o movimento; as culturas da infância; interações e sociabilidade; a afetividade, dentre outras que surgem no contexto da prática pedagógica (PEROZA; CARMARGO, 2019).

Problematizando a característica curricular do curso e as demandas advindas da relação com as escolas campo de estágios, professoras dos departamentos de Educação e Pedagogia reuniram-se na elaboração de uma proposta de curso extensionista que permitisse um debruçar mais intenso e pontual nas questões que permeiam a prática pedagógica desenvolvida com as crianças pequenas.

A respeito da importância de participação em cursos extensionistas durante a formação inicial, Dalmolin e Vieira (2015) destacam os impactos na formação afirmando que "colecionamos manifestações que constatam a qualidade diferenciada da formação dos estudantes que vivenciam, junto ao ensino, a experiência em projetos de pesquisa e extensão" (DALMOLIN; VIEIRA, 2015, p. 3).

Sendo assim, reconhecemos que a extensão universitária se constitui como um espaço formativo que se configura tanto como ação complementar da formação inicial no atendimento às necessidades dos acadêmicos do curso de Pedagogia quanto como formação continuada, ao possibilitar interlocução da universidade com os professores da Educação Infantil das redes municipais da região. Deste modo, o projeto extensionista que aqui relatamos corrobora a missão universitária de articulação entre Ensino, Pesquisa e Extensão, pois nesta instituição "a extensão universitária na UEPG é compreendida como processo educativo, cultural e científico que, articulado ao ensino e à pesquisa de forma indissociável, viabiliza a relação transformadora entre a Universidade e outros setores da sociedade" (Res. CEPE $\left.n^{\circ} 235,2009\right)$. Neste sentido, ressalta-se que, por meio da extensão, torna-se possível favorecer diálogo, questionamentos, reflexão e aprofundamento dos conhecimentos sobre Educação Infantil, crianças, infâncias e práticas pedagógicas.

\section{A proposta, os sujeitos e as ações do projeto de extensão "As Crianças, a Educação infantil e as práticas pedagógicas: entre o pensar e o fazer"}

O projeto foi estruturado na intenção de possibilitar aos participantes, por meio de palestras, pesquisas, oficinas, rodas de conversa, visitas técnicas, dentre outras, um aprofundamento do arcabouço teórico e prático referente a assuntos singulares da Educação Infantil. O objetivo foi permitir a ampliação do olhar dos acadêmicos de pedagogia e dos professores das redes municipais para a criança pequena, para as especificidades da relação teórico-prática nesta etapa da educação. Assim, convidamos os participantes a desenvolverem uma observação cuidadosa, sensível e curiosa para a criança, para que, atentos às culturas infantis, pudessem 
ressignificar os espaços e tempos da instituição, o planejamento e as relações de modo a transformar suas ações no atendimento às especificidades do desenvolvimento da criança.

Em sua primeira edição, as ações do projeto de extensão ocorreram entre os meses de maio de 2016 e maio de 2017, totalizando 52 horas de atividades, distribuídas em encontros mensais, num total de 40 participantes, dentre os quais professores das redes municipais e privadas de ensino e acadêmicos do curso de Pedagogia. Neste período, realizamos 8 (oito) encontros, distribuídos entre exibição e discussão de filme e documentário, estudos de texto, palestras, oficinas e seminário final. Todas as ações do projeto foram publicizadas em páginas de redes sociaisii a fim de divulgação para a comunidade e compartilhamento de outros materiais e informações.

O envolvimento dos participantes, os impactos das experiências vividas registradas nas avaliações, bem como a variedade de temas de interesse sugeridos para outras edições confirmaram a potência do projeto e serviram como fundamento para a reedição no período seguinte, reafirmando a necessidade tanto dos acadêmicos do curso de Pedagogia quanto de professores da rede pública de ensino na ampliação de discussões que fundamentam as práticas pedagógicas com as crianças.

Percebeu-se, ao longo do desenvolvimento da primeira edição do projeto, que a assiduidade na participação do projeto evidenciava uma necessidade da comunidade no que se refere à apropriação de conhecimentos sobre as crianças, a infância e o cotidiano da Educação Infantil. O campo da Educação Infantil tem apresentado múltiplas possibilidades para a extensão universitária, tendo em vista a diversidade de temáticas que emergem cotidianamente da prática pedagógica e a necessária ampliação dos espaços formativos que permitam reflexão, experiências e a articulação teórico-prática. Foi a partir desta constatação que delineamos uma segunda edição do projeto, demarcando os conceitos e as concepções que permeiam as especificidades desta etapa educativa, entendendo-as como determinantes para a organização das práticas pedagógicas desenvolvidas com as crianças.

Na elaboração da proposta de nova edição do projeto, optamos por tratar ora temas relacionados à creche, ora temáticas específicas da pré-escola, realizando palestras e discussões, rodas de conversa, oficinas, lanches temáticos e cine debate, no intuito de diversificar as ações e atender as necessidades e os interesses dos participantes. As ações foram distribuídas em 13 encontros:

-Encontro 1 - Palestras "Olhando para a alma das crianças: visão sistêmica da infância"; "Processo educativo da criança de 0 a 3 anos".

-Encontro 2 - Oficinas - Pintura Facial; Bebês em Movimento; Contação de Histórias; Teatro.

-Encontro 3 - Palestra "Brincar: a criança, seu corpo e possibilidades de movimento"; Oficina Dança e Educação Infantil I.

- Encontro 4 - Ofícinas - Corpo e movimento na Educação Infantil; Dobraduras; Matemática; Contação de Histórias; Pintura de rosto.

-Encontro 5 - Oficinas - Corpo e movimento na educação infantil; Dobraduras; Matemática; Contação de Histórias; Pintura de rosto. 
-Encontro 6 - Palestra e prática - Dança na Escola II.

-Encontro 7 - Palestra - Neuroeducação.

-Encontro 8 - Oficinas - Fotografia; Dobradura; Mandalas; Contação de histórias; Material pedagógico para bebês.

-Encontro 9 - Palestra - Neurociência e o desenvolvimento da criança de 0 a 3 anos.

-Encontro 10 - Oficinas - Fotografia; Mandalas; Primeiros socorros; Dobradura.

-Encontro 11 - Palestra - Documentação Pedagógica.

- Encontro 12 - Exibição de documentário - Apresentação da série Brincadiquê.

- Encontro 13 - Resgate de memórias do projeto, avaliação e confraternização.

Concluímos a segunda edição do curso no segundo semestre de 2019 com 89 participantes que, ao longo de dois anos, compartilharam muitas experiências, aprendizagens e significativos relatos que traremos no decorrer deste texto, revelando a importância de um espaço formativo e de parceria entre a universidade e as escolas de Educação Básica.

\section{Extensão Universitária: possibilidades na formação de professores de crianças pequenas}

A extensão universitária, articulada ao ensino e à pesquisa, se constitui como um dos eixos que sustentam a Universidade. Sua identidade é caracterizada pela possibilidade de interação entre a universidade e a comunidade/sociedade, como forma de propagar o conhecimento, acolher e, por vezes, responder às demandas que a comunidade cotidianamente apresenta. A ação extensionista pode, assim, se configurar como um canal de diálogo com a realidade e de serviço contínuo à comunidade. Sobre o caráter abrangente da extensão, Castro (2004, p. 14) afirma que ela se constitui como:

[...] um espaço estratégico para promover práticas integradas entre as várias áreas do conhecimento. Para isso é necessário criar mecanismos que favoreçam a aproximação de diferentes sujeitos, favorecendo a multidisciplinaridade; potencializa, através do contato de vários indivíduos, o desenvolvimento de uma consciência cidadã e humana, e assim a formação de sujeitos de mudança, capazes de se colocar no mundo com uma postura mais ativa e crítica. A extensão trabalha no sentido de transformação social.

As características da extensão, apontadas por Castro (2004), se articulam com o modo como compreendemos e organizamos o projeto para a formação de professores, pautado numa perspectiva de formação permanente, de modo a gerar transformações tanto no âmbito da constituição da profissionalidade docente de acadêmicos do curso de Pedagogia quanto de professores atuantes nas instituições de Educação Infantil. 
É possível reconhecer a importância da extensão universitária quando se avalia o impacto que advém do encontro propiciado entre o acadêmico de Pedagogia e o professor da Educação Básica e destes sujeitos aprendentes com as crianças (PEROZA; DAIANA, 2019). O diálogo estabelecido entre os sujeitos, permeado pelos estudos e pelas experiências, possibilita o reconhecimento dos saberes provenientes da prática, articulados ao campo teórico que envolve a Educação Infantil, bem como a produção de novos conhecimentos. De acordo com Jezine (2006), a vivência da extensão permite o diálogo entre a experiência popular e os saberes acadêmicos, possibilitando a articulação entre elementos da teoria e da prática.

Neste sentido, a flexibilidade curricular pode contribuir para a construção de uma formação específica, direcionada aos interesses e demandas dos acadêmicos, cuja trajetória formativa se constitui de forma personalizada e com maior sentido. Sendo assim,

\begin{abstract}
Curricularizar a extensão é ir além de creditar a extensão. É uma possibilidade de repensar as formas de ensino no contexto universitário, as relações interpessoais, a construção da cidadania em uma proposta de formação crítica, considerando que a universidade não é uma instituição à parte da sociedade, mas que possui uma capacidade ímpar no sentido de promover a reflexão crítica voltada às mudanças sociais. (PEREIRA; VITORINI, 2019, p. 28)
\end{abstract}

Sobre a creditação da extensão, Pereira e Vitorini (2019, p. 24) ressaltam que a realização de programas e projetos é fundamental para a formação acadêmica, tendo em consideração que essas ações extensionistas "têm amplitude, objetivos, nível de interação com a comunidade e articulação entre áreas mais amplas e orgânicas, diferente de ações pontuais, como eventos".

As autoras, ao tratarem da curricularização da extensão, destacam que, para além da indissociabilidade, são fundamentais a interprofissionalidade, a flexibilidade curricular e o impacto na formação do discente, a transformação social e a função social da universidade.

\footnotetext{
Interprofissionalidade possibilidade de articulação entre diferentes áreas do conhecimento articulados com problemas reais da sociedade. Nesse sentido, o curso de graduação passa a ser um espaço que vai além da transmissão de técnicas e de conhecimentos teóricos, estimulando a práxis transformadora junto à comunidade. Flexibilidade curricular: ideia de um conjunto de atividades que possibilitem escolhas ao estudante. Isso porque o currículo deve ser composto por diversas ações na ocasião da integralização. [...] Nesse sentido, a possibilidade de escolha do estudante na participação em diferentes projetos e programas pode favorecer a reflexão sobre as contribuições dessas práticas para sua formação. Impacto na formação do estudante: formação profissional na perspectiva humanista e social. É a possibilidade de o discente ter vivências para além da teoria[...]. Em outras palavras, é a extensão sendo considerada em sua dimensão pedagógica e constituindo-se em uma metodologia de aprendizagem integral e humanizadora. Transformação social: formação conectada às demandas da sociedade. É a possibilidade de produzir conhecimentos interligando criticamente o saber acadêmico ao saber popular. Função social da universidade: produzir conhecimento em diálogo com a comunidade, transformando a sociedade e a própria universidade. (PEREIRA; VITORINI, 2019, p. 22-23)
} 
A proposta do curso de extensão buscou promover experiências significativas de formação com vistas à transformação das práticas educativas desenvolvidas com as crianças. Entendemos a experiência pautada nos estudos de Larrosa (2006), que a define como aquela ação que nos passa e nos modifica. Neste sentido, a experiência pode auxiliar o professor no processo reflexivo e de redimensionamento das práticas pedagógicas.

Sobre experiências e formação de professores, Silva $(2015$, p. 13) considera que "pensar acerca de uma formação decorrente de nossas experiências, é valorizar nossa prática docente, é significá-las, logo, refleti-las, aspecto crucial na constituição docente". Neste sentido, compreendemos que esta reflexão sobre a prática integra todo o percurso de execução do projeto de extensão, permitindo a construção da identidade docente do professor de educação infantil.

Consideramos que compreender a si enquanto profissional, valorizar a própria profissionalidade e perceber a grandeza das práticas pedagógicas com as crianças pequenas pode contribuir para que a educação infantil tenha novos contornos, outras experiências e a construção de ações repletas de sentidos para os pequenos. Isso porque compreendemos que existem especificidades relacionadas às práticas desenvolvidas com as crianças na Educação Infantil, em comparação com as demais etapas da Educação Básica, ainda pouco trabalhadas no âmbito da formação docente nos cursos de formação inicial. A este respeito, Oliveira (2013, p.13-14) considera que,

\footnotetext{
As especificidades da Educação Infantil, envolvendo no processo educativo o cuidado e a atenção, [...] acrescidas ainda à informalidade e aos arranjos presentes nos processos de trabalho nas creches e pré-escolas, fruto do descaso de séculos com que essa etapa da educação conviveu, obrigam a revisão dos padrões usuais de formação docente, que têm na figura tradicional do professor que ministra uma disciplina, com seus conteúdos distribuídos em aulas de 50 minutos, o modelo de profissional a ser perseguido.
}

As especificidades do processo educativo da criança de zero a cinco anos, levam a considerar as características necessárias à formação do professor para atuar nessa etapa de ensino. Reconhecer os percalços históricos que constituem e marcam a organização da Educação Infantil no Brasil, as incoerências entre a legislação e os discursos sobre a educação da criança pequena em relação às práticas desenvolvidas, e os recentes retrocessos no atendimento desta etapa da educação leva-nos a buscar alternativas que fortaleçam a identidade docente e agreguem conhecimentos que proporcionem uma luta consciente em favor de propostas educativas coerentes e significativas nas instituições de Educação Infantil.

Rocha e Ostetto (2008) apontam que este ambiente educativo da infância deve ser pensado como possibilidade de a criança exercitar o olhar, experimentar, ver além do que está aparente, ressaltando a complexa configuração do cotidiano infantil, suas múltiplas formas de comunicar-se entre si e com o mundo. Esta forma de compreender a escola de Educação Infantil apresenta novos desafios para a formação docente e, com ela, novas possibilidades de conhecimentos, saberes e práticas com as crianças. As reflexões e ações desenvolvidas no projeto de extensão aqui apresentado se constituíram como espaço de aprofundamento a respeito da infância e dos processos educativos desenvolvidos com as crianças pequenas. Mas também, 
em um espaço de valorização da prática pedagógica de professores e equipes pedagógicas preocupadas com a qualidade do atendimento nas instituições de ensino nas quais atuam.

Ao longo do curso, pelo fato de dedicarmos alguns encontros referentes à creche $\mathrm{e}$ outros que abordavam aspectos da pré-escola, foi possível destacar elementos que, muitas vezes, passam despercebidos em outros espaços formativos. Um exemplo foi o destaque, pelos participantes, sobre os reduzidos tempos e espaços para a abordagem das especificidades do processo educativo com bebês e crianças bem pequenas, assim como as particularidades do ser professor de Educação Infantil durante a formação inicial.

No que se refere à formação de professores, Moss, Dahlberg e Pense (2003) ressaltam a importância de apoiar e promover processos de construção de identidades e socialização entre profissionais de escolas da infância, para que se promova um trabalho de qualidade com crianças. Este aspecto foi um dos mais citados nas avaliações dos participantes, salientando que o curso possibilitou uma rica aproximação entre estudantes e profissionais, apresentando uma dimensão pouco vivenciada no curso de Pedagogia. Uma das participantes, na narrativa de avaliação final do curso de extensão, nos relata:

Esse projeto me proporcionou vivenciar experiências e reflexões que o curso de Pedagogia por si só não contempla de maneira aprofundada, permitindo assim que o meu conhecimento na área da infância fosse expandido de forma significativa (Participante 14).

Mais que um espaço formativo e de encontro entre a universidade e a escola, o curso de extensão possibilitou à própria área perceber as lacunas presentes na formação docente proposta no curso de Pedagogia, com vistas à reformulação curricular do curso. Neste sentido, podemos afirmar que a interlocução entre universidade e escola gera transformações em ambos os espaços e na singularidade de cada participante, uma vez que redimensiona seu olhar e os conhecimentos que compõem a sua profissionalidade. As aprendizagens geradas pelo curso podem ser percebidas nos relatos advindos das narrativas de avaliação e de imagens dos encontros, que seguem no próximo tópico.

\section{Provocando outras propostas: memórias, vozes e aprendizagens a partir do projeto extensionista}

Os participantes, ao descreverem suas impressões e experiências nas narrativas de avaliação, remetem à articulação teórico-prática do projeto, destacando a importância das ações direcionadas aos conhecimentos teóricos, aos cuidados e práticas pedagógicas com bebês, à validade da participação de profissionais das diferentes áreas e abordagens no sentido de enriquecer as discussões sobre a criança pequena. Temas como a articulação entre o cuidar e o educar, a necessidade de conhecer como ocorre o processo de desenvolvimento da criança e as possibilidades práticas de ação com as crianças marcaram o curso na perspectiva dos participantes. 
Outro ponto ressaltado pelos participantes diz respeito à diversificação das métodologias propostas, que possibilitaram ora aprofundar conhecimentos teóricos de diferentes abordagens por meio de palestras, cine debates, estudos de textos; ora conhecer as possibilidades práticas a partir de oficinas, visitas técnicas e rodas para trocas de experiências. De modo especial, a realização de oficinas temáticas promoveu um ambiente em que os partici-pantes puderam "voltar a ser criança", mas, também, de perceber nuances das experiências que possibilitariam às crianças no cotidiano da Educação Infantil.

Além dos registros obtidos via narrativas de avaliação do projeto de extensão, o encontro de encerramento da segunda edição do projeto foi estruturado a fim de trabalharmos com as memórias, amparados na importância da história de vida de cada participante e das marcas deixadas pelas vivências conjuntas nos dois anos de encontros, diálogos, experiências e formação. As questões mobilizadoras que impulsionaram as discussões foram: Que marcas e memórias o curso deixou em você? Quais temas você destaca como relevantes? Em que aspectos da sua prática pedagógica o curso contribuiu? Que sugestões você daria para melhorar o curso em uma próxima edição?

As questões foram inspiradas nas palavras de Paulillo (1999), quando, ao abordar a importância da história de vida, afirma que os registros constituem um instrumento privilegiado para análise e interpretação, pois reúnem experiências subjetivas e contextos sociais. Sendo assim, apresentamos, em seguida, trechos e elementos extraídos dos textos que os participantes nos entregaram, destacando as principais marcas que a participação no projeto possibilitou aos envolvidos.

Ao encerrarmos o projeto, indagamos os participantes, via formulário on-line ${ }^{\mathrm{iii}}$, sobre as impressões, experiências e sugestões para o projeto. Dentre as questões, perguntamos: Qual a importância do projeto para a formação continuada de professores e para a prática pedagógica desenvolvida com as crianças pequenas? As respostam foram bastante significativas e, para a apresentação neste texto, organizadas em dois eixos: as contribuições proporcionadas pelo curso e as possibilidades para a prática pedagógica na Educação Infantil.

Com relação ao primeiro eixo, sobre as contribuições proporcionadas pelo curso para a formação docente, $100 \%$ dos sujeitos afirmam que o trabalho foi importante para sua formação. Destacamos trechos de algumas das respostas que assim expressam:

Foi de extrema importância, tanto de ideias criativas como de discussões e reflexões necessárias para a ampliação de conhecimentos (Participante 6).

O projeto foi uma oportunidade de compreender e conhecer mais a fundo a Educação Infantil, não só na visão dos professores, mas em uma partilha de conhecimento, no qual todos colaboram (Participante 12).

Foi de grande importância, trouxe enriquecimento, vivências diversificadas, podendo ter contado com pessoas de outras instituições [...] mostrando um olhar sobre várias realidades (Participante 13).

A meu ver, o projeto é rico e significativo para minha formação acadêmica e profissional, abrangendo temas de grande importância e que estão e estarão presentes no cotidiano do âmbito escolar (Participante 14). 
Os relatos nos mostram que os participantes valorizaram as discussões, as atividades propostas e a forma como foram encaminhados os encontros. Alguns destacam fatores ligados à dinâmica de organização do curso, como: ideias criativas, discussões e reflexões necessárias, vivências diversificadas, dentre outros. Os dados revelam que o formato do curso contribuiu para a permanência dos participantes, sendo uma oportunidade de compreender melhor a Educação Infantil. É possível reconhecer, nas vozes dos participantes, a necessidade de uma constante articulação entre teoria e prática, a busca de espaços de diálogo e trocas de experiências, espaços para (re)pensar seus fazeres, reestruturar saberes, construir possibilidades e, por que não, desconstruir certezas e abrir-se ao novo, ao inédito, ao real, ao simples e cotidiano.

A análise dos depoimentos nos leva às reflexões do segundo eixo sobre a prática pedagógica a partir de um olhar voltado para as especificidades da criança pequena. Dos 31 sujeitos que participaram da avaliação, 45\% (14 sujeitos) pontuaram o quanto a formação contribuiu para um olhar diferenciado para a criança, o que incide significativamente na prática pedagógica na Educação Infantil e responde aos objetivos do curso. Isso se evidencia nos trechos abaixo:

Aprendi coisas novas que irão me ajudar muito com as crianças menores, com as quais eu não tive oportunidade de trabalhar, ainda (Participante 1).

Essas reflexões abriram os meus olhos para muitas questões que envolvem a criança, fazendo da minha formação algo mais enriquecido (Participante 7).

O projeto teve um grande significado para a minha formação, trouxe novas maneiras de pensar a Educação Infantil e como esta fase que a criança vive é importante. $O$ curso agregou novos conhecimentos pela forma dinamizada como foi trabalhado. Foi excelente! (Participante 10)

A participação no projeto foi muito significativa em minha formação, me permitiu ampliar meus conhecimentos, conhecer novas práticas e ter um olhar diferenciado para a infância (Participante 20).

O curso de extensão contribui de forma significativa para minha formação e meu trabalho enquanto estagiária da educação infantil. Muito do que foi falado durante os encontros, bem como as várias aprendizagens das oficinas realizadas, eu levei para o meu dia a dia na escola. Aprendi a ver a criança de outra maneira, como um ser social que precisa ser estimulado e está em constante desenvolvimento (participante 31 ).

Notamos, nos depoimentos, que o curso contribuiu para a formação profissional dos sujeitos, ao citarem a discussão acerca das crianças menores desencadeada ao longo do curso e, também, para perceber as crianças de forma diferenciada.

Os relatos de alguns sujeitos evidenciam a excelência do projeto extensionista, tais como: "aprendi novas coisas", "trouxe novas maneiras de olhar a Educação Infantill", "permitiu ampliar meus conhecimentos e conhecer novas práticas" e "Aprendi a ver a criança de outra maneira, como um ser social que precisa ser estimulado e está em constante desenvolvimento". Isso nos leva a reconhecer que a proposta executada foi positiva e alcançou o seu objetivo inicial. 
De modo geral, os depoimentos também sinalizaram que houve articulação entre os aspectos teóricos e práticos do trabalho com as crianças pequenas. As experiências vividas no âmbito coletivo e nas trocas entre professores que atuam com a Educação Infantil e aqueles acadêmicos que ainda estão em processo de formação foram vistas como um aspecto primordial do projeto.

É válido destacar que a dinâmica do trabalho a ser desenvolvido na Educação Infantil necessita constantemente ser refletido, aprimorado, discutido e implementado de forma a colocar a criança no centro do processo educativo. Desta forma, não podemos desconsiderar a necessidade de ampliação dos processos de formação continuada, de modo a qualificar cada vez mais as práticas pedagógicas desenvolvidas com as crianças.

Outro movimento interessante propiciado pelo projeto que vale destaque é o fortalecimento das relações com as equipes dos Centros Municipais de Educação Infantil que recebem nossos acadêmicos para estágio (docência e gestão), assim como o interesse pela discussão e aprofundamento nos temas relacionados à educação da criança, que levou participantes do projeto de extensão a integrar o GEPEEDI - Grupo de Estudos, Pesquisa e Extensão em Educação Infantil (CNPq-UEPG).

Para mobilizarmos a reflexão sobre as marcas que o curso deixou, indagamos: Que marcas e memórias o curso deixou em você? Em que aspectos da sua prática pedagógica o curso contribuiu? Algumas respostas expressam essas experiências:

\footnotetext{
A convivência entre diferentes pares com realidades diversas, a parceria, a troca de experiências, o convívio com os professores (Participante 8)

As discussões sobre as brincadeiras, a reflexão sobre o que eu não permitia e após os encontros eu passo a permitir com minha turma (Participante 15)

As experiências vividas no curso fizeram com que nós pudéssemos refletir e reorganizar a nossa prática. (Participante 27)

Aprender a enxergar, conhecer, respeitar a criança, ser mediador da brincadeira [...] (Participante 63)
}

Nos depoimentos destacados, os participantes enaltecem a convivência com diferentes pares e realidades, as reflexões trazidas para o debate e que as práticas pedagógicas com as crianças foram alteradas a partir das discussões realizadas. Essas questões nos revelam o quanto a formação inicial e continuada para professores é fundamental no dia a dia das instituições de ensino e quanto o projeto deixou marcas importantes nos professores.

Kramer (2002, p. 129) propõe que "os profissionais [...] que atuam com crianças precisam assumir a reflexão sobre a prática, o estudo crítico das teorias que ajudam a compreender as práticas, criando estratégias de ação, rechaçando receitas ou manuais". Desta forma, é válido dizer que a formação dos professores se faz no encontro com o outro, na partilha de ideias, nas reflexões conjuntas, nas trocas de vivências, nas experiências partilhadas. Os depoimentos também vêm ao encontro do dizer de Drumond (2016, p. 142), ao tratar do processo de formação de professores. 
[...] discutir uma "nova" formação significa que os conteúdos dessa formação devem ser revistos, de modo a garantir aos (às) futuros (as) profissionais a aquisição de referências para atuar na docência com crianças pequenas; e isso impõe a definição de novos currículos de formação, que contemplem, além dos conhecimentos teóricos e da pesquisa empírica, as informações em contexto real, a observação nas creches e nas pré-escolas.

A infância ou as infâncias e todas as implicações que a prática pedagógica ligada a elas remete precisam ser continuamente problematizadas, estudadas, discutidas e compreendidas, como ressalta Gomes (2009).

Os participantes, ao descreverem suas impressões e experiências, referenciam a articulação teórico-prática do projeto, destacam a importância das ações direcionadas aos conhecimentos teóricos, aos cuidados e práticas pedagógicas com bebês, a validade da participação de profissionais das diferentes áreas, enriquecendo as discussões sobre a criança pequena e a articulação cuidar/educar, assim como a realização de oficinas que lhes permitiram "voltar a ser criança".

Considera-se que esta experiência foi possibilitada pelo fato de termos estruturado um projeto de extensão pautado em diferentes metodologias, na intenção de mobilizarmos o olhar, a escuta, a reflexão, provocar sensações e emoções para a produção de outros de conhecimentos sobre si, enquanto professor, e sobre as crianças, as infâncias e a educação infantil.

Dentre as ações citadas nos registros dos participantes no formulário de avaliação está a menção ao café, que denominamos café pedagógico. Buscamos relacionar o momento do lanche a temas valiosos ao pensarmos a infância, entendendo o momento da alimentação como rico e repleto de manifestações culturais e o alimento como uma linguagem.

Os estudos de Cavallini e Tedeschi (2011) abordam as experiências com a comida nas instituições de Reggio Emilia, na Itália, e nos instigam a pensar os gostos, a diversidade religiosa, as indicações médicas, entre outros elementos que integram o alimentar-se. As autoras tratam da importância de ouvir as famílias e seus hábitos, ressaltando que o momento da alimentação é espaço e lugar de encontro e de relacionamento com o mundo.

Em cada encontro, vivenciaram-se diferentes formas de organização do lanche e dos espaços para a alimentação, a fim de que os participantes pudessem experienciar o encontro, dialogar, transitar entre diferentes elementos e saborear diferentes alimentos. 
Figura 1 - Momentos do Café Pedagógico

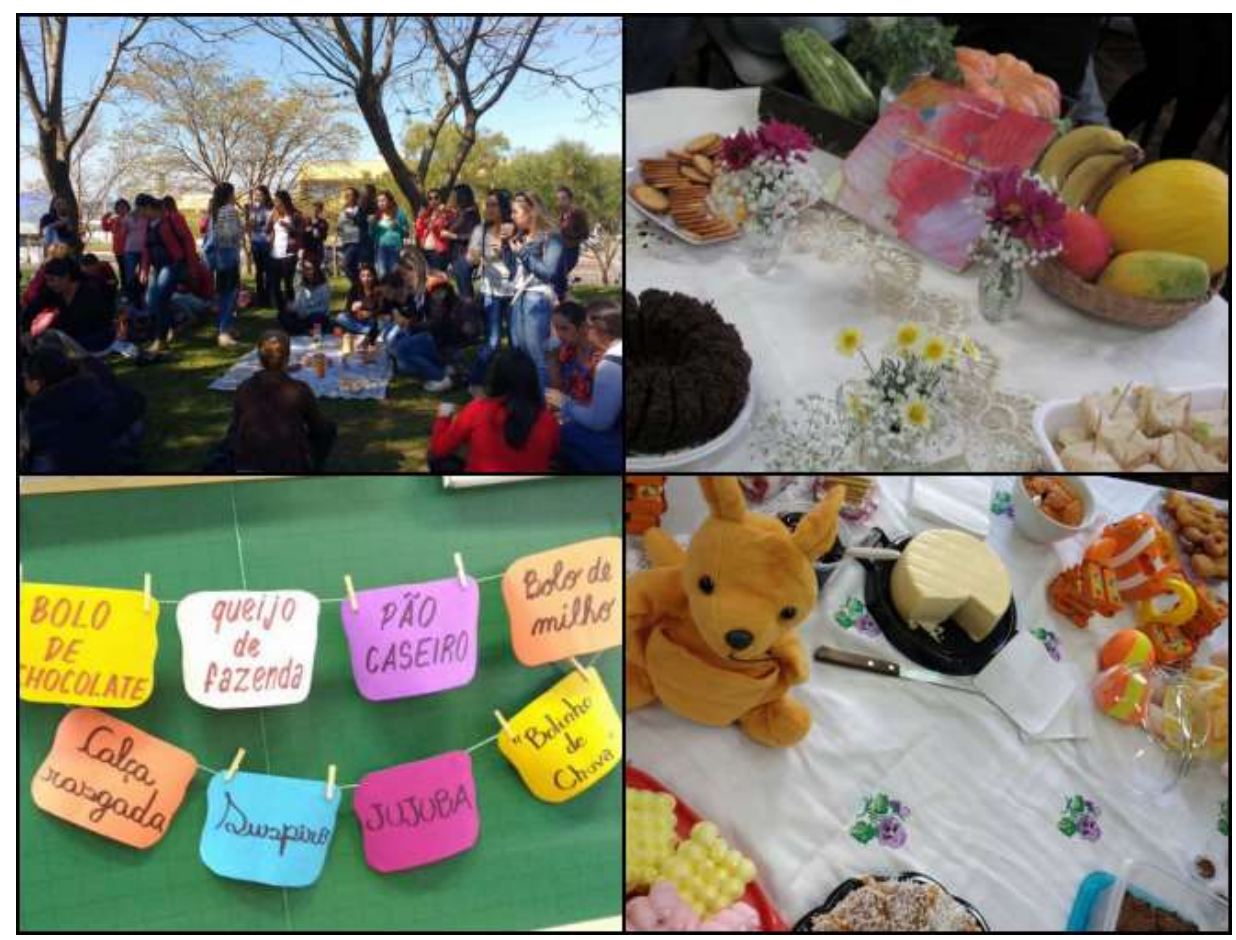

Fonte: Registros do projeto - arquivo das autoras.

As experiências vividas nos momentos de café pedagógico, para além de incentivar outras reflexões e mobilizar outros olhares para o alimento e os espaços, mobilizaram os participantes a falarem para si, suas infâncias, sua construção pessoal e profissional por meio das memórias provocadas por cheiros e sabores, principalmente no café pedagógico "linguagens da comida e sabores de infância".

Ao analisarmos os dados provenientes da avaliação do projeto de extensão, foi possível verificar que um dos elementos centrais nas falas dos participantes é o brincar, a redescoberta do prazer de envolver-se nas brincadeiras e a experimentação de outros materiais, do corpo e dos movimentos. Esta experiência

[...] provocou os cursistas a reviver memórias do brincar [...] movimentos do corpo, práticas prazerosas. Um professor feliz irá transmitir felicidade aos alunos (Participante 45).

Ao indagarmos os participantes sobre temas relevantes para uma próxima edição do projeto de extensão, temas como neurociência, educação especial e bebês, a inclusão, entre outros, aparecem como os mais mencionados. 
Figura 2 - Nuvem de palavras dos temas sugeridos

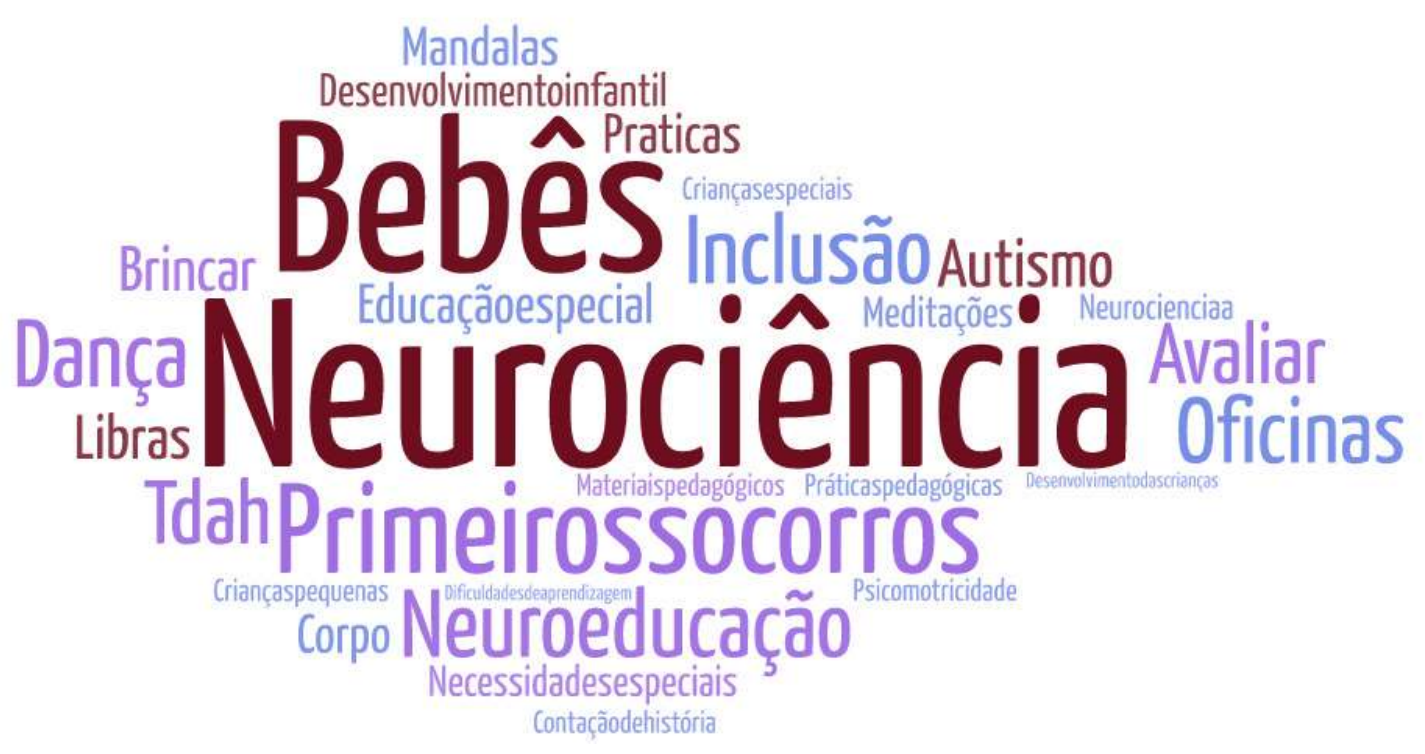

Fonte: Avaliações dos participantes

Como foi possível observar, o projeto de extensão foi significativo em diversos aspectos, como ressaltado por diferentes participantes. Neste sentido, podemos afirmar que o curso atingiu seus objetivos e possui uma perspectiva de continuidade como uma ação complementar, por um lado, à formação dos acadêmicos do curso de Pedagogia e, por outro, como espaço de formação continuada para profissionais que atuam na Educação Infantil.

\section{Tecendo algumas considerações e avistando possibilidades}

Ler atentamente os relatos apresentados foi uma forma de conhecer a percepção dos participantes sobre a importância do projeto. Sem dúvida, esta oportunidade nos fortalece quando percebemos que a metodologia escolhida - leituras e discussões, rodas de conversa, exibição e debates de documentários, oficinas, dentre outras - contribuiu com a formação profissional e com as práticas de cada um que esteve envolvido.

Os dados revelam que houve avanços na formação profissional dos participantes do projeto, ao passo que provocou uma oportunidade de repensar a prática pedagógica de modo a compreender melhor as temáticas discutidas e ter condições de propor experiências diferenciadas e significativas para as crianças em suas instituições.

A análise do curso à luz das avaliações reafirma a importância de projetos de extensão que se constituem em estreita relação com as demandas advindas da comunidade educativa, as instituições de ensino, articulando-se com a proposta curricular dos cursos de formação docente. 
Dentre as possibilidades, com o atual encaminhamento legal que insere a curricularização da extensão por meio do Plano Nacional de Educação (2014-2024), temos essa indicação como uma das estratégias para cumprimento da Meta 12, que pretende elevar a taxa de matrícula na educação superior, destacando que se deve assegurar, no mínimo, 10\% dos créditos curriculares exigidos para a graduação em Programas e Projetos de extensão universitária, com prioridade para áreas de grande pertinência social (PDI - UEPG, p. 44).

Mediante as avaliações, bem como as reflexões a respeito da importância da extensão universitária apresentadas, considera-se a necessária organização de propostas, o desenvolvimento de projetos e demais ações vinculadas à realidade social de cada comunidade educativa, como forma de consolidar o diálogo entre a instituição universitária e a comunidade, a fim de que a curricularização da extensão se constitua com sentido e eficiência.

No que diz respeito à formação de professores, avistamos as possibilidades de ações que possam ampliar as ações formativas, tendo em vista que a organização curricular dos cursos de Pedagogia não consegue abranger a demanda de temas e particularidades advindas do cotidiano na escola.

No tocante à educação infantil, demarcamos que os temas emergentes das falas dos participantes do curso já tratados acima são candentes para a formação de professores de crianças que nem sempre são contemplados ou aprofundados no espaço do curso de formação inicial.

Por fim, ressaltamos não apenas a importância do curso oferecido aos participantes - profissionais da educação infantil e acadêmicos -, mas anunciamos a continuidade do projeto a partir do interesse de outros sujeitos que receberam indicações do curso, bem como dos acadêmicos que têm demonstrado a intenção de aprofundar os estudos e realizar pesquisas referentes às práticas pedagógicas na Educação Infantil.

\section{Referências}

AZEVEDO, H. H. O. de. Educação infantil e formação de professores: para além do cuidar-educar. São Paulo: Editora Unesp, 2013.

BRASIL. Lei n. 9.394 de 20 de dezembro de 1996. Estabelece as Diretrizes e Bases da Educação Nacional. Diário Oficial da União, ano CXXXIV, n. 248, p. 27.833-27.841, 23 dez. 1996.

BRASIL. Lei n. 13.005, de 25 de junho da 2014. Plano Nacional de Educação. Aprova o Plano Nacional de Educação e dá outras providências. Brasília, 2014. Disponível em: http://pne.mec.gov.br. Acesso em: 12 maio 2021. 
CASTRO, L. M. C. A universidade, a extensão universitária e a produção de conhecimentos emancipadores. In: REUNIÃO DA ANPED, 27., 2004. Caxambu. Anais [...]. Caxambu, 21 a 24 de novembro de 2004. Disponível em: http://27reuniao.anped.org.br/gt11/t1111.pdf. Acesso em: 12 maio 2021.

CAVALLINE, I.; TEDESCHI, M. As linguagens da comida: Receitas, experiências, pensamentos. São Paulo: Phorte, 2011.

DALMOLIN, B. M.; VIEIRA, A. J. H. Curricularização da extensão: potências e desafios no contexto da gestão acadêmica. In: EDUCERE - CONGRESSO NACIONAL DE EDUCAÇÃO, 12., 2015, Curitiba. Anais [...]. Curitiba: PUC-PR, 2015. Disponível em: http://educere.bruc.com.br/arquivo/pdf2015/20159 9517.pdf. Acesso em: 12 maio 2021.

DIAS DE LIMA, S. Formação inicial em pedagogia: um outro olhar para as infâncias. Tese (Doutorado em Educação) - Universidade Federal do Rio Grande do Sul - UFPRGS. Porto Alegre, 2015.

DRUMOND, V. A Centralidade do Estágio na Formação de Professores(as) de Educação Infantil. In: CANCIAN, V. A.; GALLINA, S. F. da S.; WESCHENFELDER, N.

Pedagogias das Infâncias, crianças e docências na Educação Infantil. Santa Maria:

UFSM, Centro de Educação, Unidade Ipê Amarelo. Ministério da Educação, Secretaria de Educação Básica, 2016.

GOMES, M. de O. Formação de professores na Educação Infantil. São Paulo: Cortez, 2009.

JEZINE, E. A. A crise da Universidade e o compromisso social da extensão universitária. João Pessoa: Editora da UFPB, 2006.

KRAMER, S. Com a pré-escola nas mãos: uma alternativa curricular para a educação infantil. 12. ed. São Paulo: Ática, 2002.

LARROSA, J. Pedagogia profana: danças, piruetas e mascaradas. Belo Horizonte: Autêntica, 2006.

MOSS, P.; DAHLBERG, G. PENCE A. Qualidade na educação da primeira infância. Porto Alegre: Artmed, 2003.

OLIVEIRA, D. A. A profissão docente na Educação Infantil. Docência na Educação Infantil. Salto para o Futuro, Ano XXIII, boletim 10, jun.2013. Disponível em: https://cdnbi.tvescola.org.br/contents/document/publicationsSeries/17204610 DocenciaEdu cacaoInfantil.pdf. Acesso em: 12 maio 2021. 
PAULILlO, M. A. S. Pesquisa qualitativa e a história de vida. Serviço Social Rev., Londrina, v. 2, n. 2, p. 135-148, 1999.

PEREIRA, N. F. F.; VITORINI, R. A. S. Curricularização da extensão: desafio da educação superior. Interfaces - Revista de Extensão da UFMG, Belo Horizonte, v. 7, n. 1, p.19-29, jan./jun. 2019.

PEROZA, M. A. R.; CAMARGO, D. A experiência de encontro entre sujeitos aprendentes: aspecto da formação docente vivenciado no estágio supervisionado em docência na educação infantil. Revista de Educação, Ciência e Cultura, Canoas, v. 24, n. 1, 2019.

ROCHA, E. A. C.; OSTETTO, L. E. O estágio na formação universitária de professores de Educação Infantil. In: SEARA, I. C.; DIAS, M. de F. S.; OSTETTO, L. E.; CASSIANI, S. (Orgs.). Práticas pedagógicas e estágios: diálogos com a cultura escolar. Florianópolis: Letras Contemporâneas, 2008.

SILVA, M.C. da. Formação de professores para a infância: a experiência como constitutiva do "formar-se". In: ANPED SUL, 10., 2014, Florianópolis. Anais [...]. Florianópolis, out. 2014.

UNIVERSIDADE ESTADUAL DE PONTA GROSSA. Pró-Reitoria de Planejamento.

Diretoria de Avaliação Institucional. PDI: Plano de Desenvolvimento Institucional: 20182022. Ponta Grossa, UEPG. 2018. v.1; 266p.

\footnotetext{
Notas

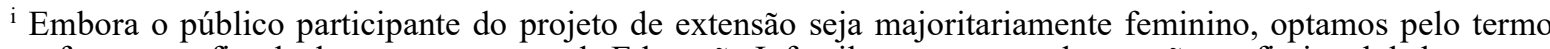
professores, a fim de demarcar o campo da Educação Infantil como espaço de atuação profissional de homens e mulheres.

${ }^{\text {ii }}$ Mais informações https://www.facebook.com/primeirainfanciaepraticaspedagogicas2016; https://www.facebook.com/gepeedi

iii As falas dos participantes foram obtidas por meio do formulário de avaliação do projeto.
} 